\title{
Risk Assessment of Radio Frequencies and Public Information
}

\author{
Marc Poumadère \\ Institut Symlog - Risk Governance . 262, rue Saint-Jacques 75005 Paris, France \\ tel: 33140460029 e-mail: poumadere@wanadoo.fr
}

\author{
Anne Perrin \\ Biomedical Research Institute of the Army - CRSSA, Department of Radiobiology \\ 24, avenue des Maquis du Grésivaudan 38700 La Tronche, France
}

\begin{abstract}
The rapid, worldwide development of mobile phones is accompanied in many countries by public concern over the possible health risks of radio frequencies (RF). National and international health agencies have undertaken risk assessments, and an in-depth study was rec ently conducted with the French Agency on Environment and Health Safety (AFSSET). This paper builds upon this experience, considering not only risk assessment as it bears upon a physical object (RF), but also concerning activities largely characterized along psychosocial dimensions (mobile phone use). It becomes a theoretical and methodological challenge, however, to integrate these characteristics into the assessment process. The research of causal links between RF exposure and subsequent biological or health effects is the main focus of expology. Applied in the AFSSET assessment, the results are in line with previous reviews of research: biological response appears nonexistent or limited to a few cases, and there is no evidence of RF health effects. Considering these results, we specifically look at how information may play a role in the construction of the psychological and social relationship to risk, with a particular emphasis on potential health impacts. In that context, we explore the lesser-known notion of socio-cognitive exposure, char acterized by chronic exposure of populations to potentially worrying information when various health consequences are evoked in the literature and by the media. Th is raises the possibility of a link between risk information and health. Several specific explanations are explored here, notably: nocebo, stress, and the symmetry rule.
\end{abstract}

Keywords: Radio frequencies; Mobile phone; Risks; Environment; Health; Psychological Social; Chronic exposure; France; Electromagnetic hypersensitivity

\section{Introduction}

Risks can be positioned along a dimension, ranging from confirmed risks t hat can be objectively controlled, to suspected risks that are more difficult to assess and manage. In the case of RF and mobile phones, with health risks remaining outside quantification, the mere suspicion of risk nonetheless impacts the collective and individual imagination of a very large population. Risk perception research has shown how information, more so in most cases than direct personal experience, shapes the individual and collective relationship to risk objects or activities. ${ }^{1}$ Research in social amplification of risk has shown that the attention given to a risk ob ject or activity can be either soc ially amplified or attenuated, regardless sometimes of its dangerous nature as measured by health or environmental impacts. ${ }^{2}$ Practically speaking, this often means that the scale of the activity in question and the degree of controversy over its perceived riskiness are frequently uncorrelated with the actual magnitude of the hazard. When there is insufficient evidence to indicate that a hazard exists, additional scientific data is required, more so to re duce uncertainty than to provide a c lear conclusion. Uncertainty, especially as it relates to public health risks, can fuel controversy, as politicians await the reports and recommendations from their health authorities. Yet, no matter how essential a step scientific risk assessment may be, it does not provide a ready-made decision for risk managers. Meanwhile, studies reveal that part of the public perceives radio signals transmitted by mobile phones and base stations as a potential health risk. ${ }^{3}$ In this situation it is tempting for politicians to invoke the precautionary principle: policy assumptions at that level are that this approach cannot hurt and will reassure populations. However, this policy assumption ought to be verified: as we sha 11 discuss in section 5, precautionary advice can impact risk perceptions.

To position the risks of RF within a larger perspective, several levels of environmental risk analysis issues over time can be examined. The development of the chemical and nuclear industries during the second half of the 20th century 
presented notable benefits to society, along with a new type of risk: while the probability of accident remained low, the catastrophic consequences of a potential accident were quite high. This presented several challenges in terms of risk assessment and decision-making, and the $\mathrm{m}$ andatory disclosure of haz ard information became part of communicating risk to the public ${ }^{4}$ Subsequent studies into the relationship between environment and health were undertaken, particularly in light of the presence of low levels of dangerous substances in the air, soil or water. This type of pollution can stem from various sources, including industries, transportation, or the agricultural use of pesticides, to name a few. For this sort of risk analysis, the difficulty lies in assessing the health effects of $\mathrm{c}$ hronic exposure to low doses of potentially dangerous substances, as well as the hazards posed by the combination of low-dose exposure to various substances. ${ }^{5}$ A third type of risk can be seen with electromagnetic fields as a striking example. Though the characteristics of RF as a physical agent have been known for more than a cent ury, they were not previously identified as hazardous to human health, even despite public concern over the ea rliest applications of wireless technology at the beginning of the 20th century. That mobile telephone usage has become so global, with an estimated 5 billion or $\mathrm{m}$ ore users, is an un precedented phenomenon which leads us to fra me the question of risk differently. While the majority of risky objects and activities are assessed through the routine application of $t$ he appropriate processes (which involve the separation of assessment and management), some risks appear embedded in a larger social context (e.g. the sudden omnipresence of mobile phones in everyday life). When this is the case, risk assessment faces additional challenges, and new approaches must be found. The shift from risk gov ernance to the governance of public concern ${ }^{6}$ illustrates this search for new approaches, but it might overlook the role of information as a mediating variable between a risk issue and health.

With the objective of dealing with both the health aspects and the social dimension of RF, this paper presents first an assessment of risk based upon human exposure to RF, along with the guidelines for regulating this exposure. In addition, we consider the fact that populations are also exposed to the massive and rapid penetration of mobile phones in the private, professional and public spheres, in addition to being exposed to RF as a physical threat. The notion of socio-cognitive exposure is then introduced, along with a discussion of the possible effects of large populations being exposed to worrying information when potential health impacts of R F are reported. Certain ca usal relationships, which could possibly be related to symptoms reportedly associated with radio frequencies, are also explored: stress, the nocebo effect, and the symmetry rule.

\section{Radio frequencies and Health}

In this section, we offer a general overview of the interaction of radiofrequency emitting sources with biological systems, and of the existing guidelines for public safety legislation. We discuss more specifically the level of exposure of the population through mobile phones, the state of current scientific knowledge allowing risk assessment, and electromagnetic hypersensitivity.

\subsection{Radio frequency emitting sources and intera-ction with biological systems}

Electromagnetic fields are increasingly used for methods of wireless communication, such a s telephones, Wi-Fi, radiofrequency identification (RFID), etc. Usually called radio frequencies (RF), they take place in the non ionizing radiation part of the total electromagnetic spectrum due to the fact that they do not carry enough energy to induce damage within molecules through chemical ionizing reactions. Nevertheless, there is an interaction of RF with the matter it encounters; for example, when RF interacts with the human body, the radiation energy is partly absorbed by the body's tissues. Since 1975, this absorption has come to be characterized by the Specific Absorption Rate (SAR), expressed in watt per kilogram $(\mathrm{W} / \mathrm{kg})$. This value depends on the RF power received by the matter itself (incident power in watt) related to the power and the distance of the RF emitting source. The SAR also de pends on th $\mathrm{e}$ physicochemical characteristics of the ex posed object, as well as its shape, volume and environment. The SAR value is not easy to assess, especially for living models (animal, human). It must be calculated by numerical simulation and validated by experimental measurements of electric fields or temperatures of the exposed matter. When the power level of the emitting device is sufficient, interaction between matter and RF can lead to a high SAR level (thermal level). A subsequent increase in the temperature of the matter and molecular and/or biological effects might then occur (thermal effects).

\subsection{Safety guidelines and public exposure}

In the leg islation, safety reference levels regarding the general public's exposure to RF are the basis for the different legal and regulatory approaches being pursued in many countries. For the most part, the reference levels are based on the International Commission on Non-Ionizing Radiation Protection (ICNIRP) guidelines. ${ }^{7}$ In the US, the guidelines are established by the Institute of Electrical and Electronics Engineers (IEEE), following a similar procedure which consists of an ongoing, critical and rigorous survey of scientific literature on the subject ${ }^{8}$ The thermal effects of radio frequencies are described and serve as a reference for the safety guidelines, which include a safety factor of 50 for

Published by Atlantis Press

Copyright: the authors 
the general public. The aim is to ensure that human exposure to RF emitting devices does not induce a hazardous thermal SAR level even in the case of excessive use, with particular attention paid to $\mathrm{m}$ ore vulnerable subpopulations (the elderly, children, etc.).

\subsection{Radio frequency exposure of the population to mobile telephones}

In mobile phone technology, the cell phone handset, which is both a receptor and emitter, represents the main source of RF exposure for the general public; the resulting SAR into the head is 10 to 100 thousand times higher than that resulting from base station RF emissions. The environmental exposure level due to the latter can be assessed by measuring the electric component of the electromagnetic field with appropriate probes (expressed in volt per meter: $\mathrm{V} / \mathrm{m}$ ). The electric field must not surpass the limits designated by the current rules regarding mobile phone frequencies, ensuring that the ICNIRP guidelines will not be exceeded in terms of SAR: e.g. in France, $41 \mathrm{~V} / \mathrm{m}$ (GSM $900 \mathrm{MHz}$ ), $58 \mathrm{~V} / \mathrm{m}$ (GSM $1800 \mathrm{MHz}$ ) and $61 \mathrm{~V} / \mathrm{m}$ (UMTS $2100 \mathrm{MHz}$ and Wi-Fi $2400 \mathrm{MHz}$ ).

In the environment, the ambient values are low, generally below 1 or $2 \mathrm{~V} / \mathrm{m}$, and of ten smaller than those resulting from radio emitters. In accordance with the laws of physics, the intensity is greater at distances of 50 to 200 meters from the base stations as opposed to directly under the station, in light of the fact that they are designed to be directional ${ }^{9}$ The measurement of the electric field is quite easy to conduct with appropriate probes, but it is o nly appropriate at a distance from the emission source where the electromagnetic wave is well organized (far field). It is not suitable for the cell phone handset which is used in near field close to the head. In this case, the SAR value is the only reference unit.

\subsection{Scientific research, knowledge and risk assessment}

In terms of risk policy and management, taking into account the very large number of people exposed, it is clear that even a very small health risk cannot be neglected. The objective of current research is therefore to find answers to the following question: do non thermal effects due to RF exposure exist below the current established limits?

For telephones, scientific experts do not consider that mobile phone base station exposure may be hazardous for human health, considering the ve ry low exposure level. Scientific research is primarily focused on exposure to cell phone handsets, given that the exposure levels generated are higher and that the emitting source is used close to the head.

This research activity became intense in the 1990s, following a lawsuit where cell phone use was blamed in the death of a woman diagnosed with brain cancer. Experimental studies performed in vivo and in vitro, as well as epidemiological studies on human populations, have be en carried out worldwide to investigate the effects of R F exposure on bi ological reactions, physiological functions, behaviour and diseases, especially cancers. Since then, radiofrequency health risk assessment has been regularly carried out all over the world, giving rise to expert's reports. The conclusions rely on critical reviews of relevant scientific literature by multidisciplinary panels of confirmed experts. An observed effect can be considered established, however, only when it has been described in high quality peer-reviewed scientific papers, and could be replicated, and/or when the results of different complementary studies are consistent with each other. For example, this means that if one in vitro study showed a DNA damaging effect, it would not necessarily constitute a hazard (especially if the effect is weak) if no effect of exposure in animal or on human health is found. Furthermore, it should also be noted that a biological effect is not necessarily related to an adverse (or beneficial) health effect.

In France, following reports edited in 2000 and 2005 , AFSSET's report of October 2009 deals with all studies published between January 2005 and April 2009, including 12 reports produced during this period in $\mathrm{d}$ ifferent countries $^{10}$ Taking into account the anterior status of the knowledge, the general conclusion was that "the data from experimental research thus far indicates neither short nor long-term health effects. The same goes for epidemiology concerns: no short-term effects have been discovered, though questions do remain over the potential effects of longer-term exposure, even though no biological mechanism suggests such effects". The $r$ eport also mentioned that decreasing the ambient RF exposure limits to the often cited $0.6 \mathrm{~V} / \mathrm{m}$ value was not scientifically justified.

Since 2009, the INTERPHONE was published. ${ }^{11}$ It is the largest international epidemiological study conducted to date, focusing on brain cancers - i.e. glioma, meningioma, accoustic neuroma - and individual mobile phone use. It remains inconclusive without providing proof of an increased risk.

Several reports have also been published by other groups, such as, for instance, the ICNIRP ${ }^{12}$, the Executive Agency for Health and Consumers ${ }^{13}$, and the Swedish Independent Expert Group on Electromagnetic Fields . ${ }^{14}$

In examining the existing data, no causal relationship between low level RF exposure and adverse health effects can be established. There is a large consensus that the risk, if existant, would be very small. Nonetheless, debates over the possibility of long term effects continue. More generally, a recent WHO summary on the health effects of RF exposure corroborates this current state of the available knowledge..$^{15}$

\subsection{Electromagnetic hypersensitivity (EHS)}

It has been estimated to affect anywhere from 1 to $10 \%$ of the population, and exhibit quite noticeable geographical 
variability in terms of pr evalence and the reporting of relevant symptoms. Individuals with EHS suffer from a variety of non specific and common health symptoms self-attributed to RF. Some of them are so severely affected that they must stop working and may become withdrawn from society. Of all groups, women and mi ddle-aged individuals with a higher education are the most affected. A set of convergent associated signs suggests that individual neuro-psychic factors may play a part in this condition. ${ }^{16} \mathrm{~A}$ number of stu dies were carried out to inv estigate whether EHS volunteers are able to distinguish RF exposure compared to simulated exposure (sham) and if they have a different perception of RF exposure when compared with control subjects. The results showed no evidence for a causal relationship between these symptoms and RF exposure in double blind experiments, and several studies have moreover suggested the existence of a noc ebo effect and somatisation..$^{17,18}$

Similar symptoms were reported for cases of multiple chemical sensitivity (MCS), sick building syndrome (SBS), chronic fatigue syndrome and Gulf war syndrome. For each of these, a more general applicable name, which describes sensitivity to environmental factors, is referred to as Idiopathic Environmental Intolerance (IEI) by the WHO ${ }^{19}$

\section{Social concerns and risk assessment of mobile phones}

In several countries around the world, the use of mo bile phones has become a controversial issue. Some argue that a significant and continuously increasing number of people worldwide are threatened by the biological effects of radio frequencies as they may negatively impact one's health. In light of this potential threat and the scientific uncertainty associated with attempts to assess the actual risk, the situation warrants action that would lower RF emissions and reduce public exposure to such hazards, in particular for children, in application of the precautionary principle.

The precautionary principle, which entered the French Constitution in 2005, stipulates: "When the realization of a damage, although uncertain on the basis of available scientific knowledge, could affect the environment severely and irreversibly, public authorities insure that, by application of the precautionary principle and within their attributed domains, proper risk assessment is undertaken and that temporary and proportionate measures are adopted so as to prevent the realization of the damage." From this excerpt, it is clear that the evaluation of risks represents an important application of the precautionary principle as prescribed in the French constitution. In fact, it could even be argued that risk evaluation is indeed the first priority, even before considering the eventual application of protections or regulatory measures with which the precaution principle is more typically associated. Risk assessment entails the identification of dangers to health resulting from exposure to an agent identified as a risk factor, and aims at measuring the magnitude and likelihood of a negative impact on health or the environment. In order to prevent an evaluation from being influenced or pre determined by a political power, economic issues, or the social amplification of risk, an established principle in risk-analysis consists of separating the evaluation of risk from the way in which this information is communicated and the risk is managed. This separation was not always the norm, but became more standard after developments towards the end of the 1970s. Dividing up the different components of ri sk-analysis (i.e. assessment, management, and communication) allows for a $\mathrm{m}$ ore thorough, systematic process and thus facilitates more careful analysis of the various issues at play, most notably between science and po litics. This does no $t$ exclude the possibility of a pluralist approach, based on a $n$ interdisciplinary or tra nsversal methodology with the participation of associated representatives and the actors who are directly involved. Members of the local population at the source of the "signal" can be included, taking into account their relationship to the environment. In stu dying these subjects, it is important to take an approach sensitive to the linguistic and interpersonal dimensions of their expression. If the thre e steps of risk analysis appear to be formally defined and separated, the governance of risk grants those directly affected a form of $r$ ecourse in deliberation. In France, AFSSET is situated at the intersection of science and policy, as on the one hand it is in charge of organizing collective and multidisciplinary scientific expertise of ris k and promoting areas of research, and on th e other hand it provides policy advice. This process is specifically appropriate for objects or activities marked by complexity, uncertainty, and ambiguity. ${ }^{20}$ It can be equally useful when several agents and substances are evaluated simultaneously, taking into account their possible combined effects on the environment, though the formal method of risk analysis was initially developed to treat one risk at a time. The aim here is to attain a higher level of efficacy, whether via an evaluation of risks through pluralist scientific assessments or through management and communication with different forms of collective deliberation, given the reality of complementary and otherwise not easily accessible resources. The efficacy depends on a commitment by those persons potentially affected to cooperate in co nfronting the complexity, the incertitude, and the ambiguity of risk. This type of involvement with stakeholders, based on an organized and collective initiative centered on their own concerns, would require surpassing the existing polarization between opponents and investigators, who tend to take a reductionist stance on the issues at hand, and transform the debates into trials and spectacles attracting media attention.

Within the context of France and other European Union countries, there exists a high level of public concern about 
the health risk of radio frequencies, unless there are other risks which are considered more pressing and which have yet to be dealt with, such as chemicals, foods or drinking water, as measured by risk perception surveys. ${ }^{21}$ The risk of mobile phones has become a topic of controversy, with each side of the debate featuring strongly opposing points of view. Such controversy is neither surprising, nor a recent phenomenon: the dangers of w ireless technology were acknowledged almost one century ago, as documented in an article published by the New York Times in $1914 .^{22}$ The article, "Persistent Theory of Wireless Peril", reports on French newspaper articles suggesting the capacity of Hertzian waves to ignite gun powder and cause an explosion at a coal mine, a notion strongly rejected by the scientists of those days. From very early on, fierce debate and controversy plagued the fields of risk assessment and risk management. In 1984, no less than 162 controversies appear to be associated with technological risks. ${ }^{23}$ It should be noted, however, that controversies are not unique to the risk domain and may potentially arise whenever there exist opposing points of view or interests. Controversy provides a traditional base for media coverage and, more importantly, attracts the attention of the public, regardless of any ac tual correlation to the degree of risk of a particular potential hazard. Conversely, the absence of controversy does not mean the absence of risk, or the absence of severe impacts in terms of public health. Some acute threats, while being scientifically identified as such, can be socially minimized, as wa s the c ase, for example, with the heat waves of 2003, which caused some 20,000 deaths in France. ${ }^{24}$ In other $w$ ords, social controversies are not indicative of the nature or severity of a risk. This poses a political dilemma: while attention to the public's concerns is surely important, public health must also be managed according to objective criteria like mortality and morbidity. This nec essitates a carefully balanced approach that prioritizes which risks a re most pressing, a task best performed by a neutral entity like the government. It is important to di fferentiate assessments dealing with risks associated with future projects from those being applied to existing equipments, such as the $\mathrm{c}$ ase of wireles $\mathrm{s}$ communication systems. In the case of the former, the analysis can be performed in tandem with public hearings and inquiries preceding the realization of technical projects, which allows for the consideration of $i$ ssues such as acceptable risk and choices (both of technology and society) and associated value judgments. In the latter case, populations can feel confronted with an invasive technology and its possible risks without having previously participated in public hearings and debates. Mobile phone technology falls into this second category. The implementation of network coverage over an entire country was framed, in most countries, as a public good, with no associated health risk. In France, it was shown that public ire was mainly directed against network antennas and or iginated in local protest movements in the absence of a ny proven adverse health effects. $^{25}$ When, after a risk c ontroversy, public concern comes to be a major issue, the scientific assessment can play a social role of retroactive adjustment: it can contribute indirectly to the social debate and, in some cases, facilitate social appropriation of the new technology at hand. Nevertheless, the sit uation is paradoxical because while mobile telecommunication has sp read rapidly around the world, illustrated by massive increases in public subscriptions to this technology, public concern over possible associated health risks has simultaneously increased in certain countries. It is to be note $d$ that people expressing greater concerns are among those estimating they are sufficiently informed. ${ }^{26}$

\section{Characterization of mobile phones as a social object}

Social science research in the risk domain is based on three distinct levels. The first deals with methods and concepts allowing for the definition and im plementation of ris $\mathrm{k}$ management procedures and is linked to decision analysis and policy. The sec ond level concerns the organization of collective deliberation and the structuring of debate in such a way as to incorporate the relevant stakeholders into the process of risk governance. The third level is the characterization of ob jects and sit uations associated with risk, in particular through studying the social and psychological aspects of risk, thus contributing to risk assessment. Within our approach, we consider psychosocial repercussions not only to be a consequence of the uncertain nature of the hazards of RF, but also as just one of the factors which could have an impact on health. This could occur in particular through public exposure to the large amount of information suggesting health damage associated with wireless technologies, especially antennas and cell phone handsets.

The massive and $\mathrm{r}$ apid worldwide diffusion of mobile phones appears to be an unprecedented technological event in human history. ${ }^{27}$ That these mobile networks and the ir physical installations exist quite literally everywhere has a profound impact on society and has changed the lifestyles of the populations affected. This mere fact is rarely considered in the relevant analyses and debates, even though it is probably a key ca use of significant observed cultural changes around the world.

Studies on mobile phone diffusion often focus on the main advantages of the technology, which explain its widespread success: users are able to communicate at a distance (which was not previously the case for a large part of the global population), they can access information, and they can be reached anywhere and at any moment. Among the risks some times acknowledged, cell phone use wh ile driving is bes t known, although researchers often qualify 
their concerns by emphasizing the simultaneous benefits of having a mobile phone in the car in case of an accident or emergency.

Regarding the health effects of human exposure to th e electromagnetic fields inherent to $\mathrm{m}$ obile phones, this technology can be con sidered a double risk: an individual risk associated with the handset that can be controlled; and a collective, or environmental, risk associated with the base

stations that no one individual can control and to which everyone is subjected. In th is context, cell phone handsets and base stations give rise to a paradoxical management situation with ample opportunity for confusion in the general population. Subsequent to their massive diffusion, radio frequencies have become the object of numerous scientific studies.

As a conse quence, one can also note the para llel development of worldwide mobile phone networks and the publication of studies related to health risk. What conclusions can we draw from this correlation?

Scientific attempts to investigate radio frequencies as a physical agent are nothing new. However, it does appear that the growing number of studies on the biological effects of RF are linked to the development of mobile telephones, not only as a technology, but above all as a widely diffused social object. We can therefore see these publications as a form of response to the worries and concerns of affected populations.

This highlights the soc ial function of the scientific research and analysis, and draws attention to the fact that it is not limited to scientific issues. One byproduct of this research is for its part the uneven political treatment of risk and of its assessment around the world. For example, in some places, local populations recognize the he alth concerns of wind energy installations (noise, stroboscopic effect, infrasound). However, due to the exposed populations not being large enough (in contrast with populations exposed to radio frequencies), and in the absence of a significant social movement, no coordinated action is undertaken.

With regards to the content of studies on radio frequencies, Table 1 give s an ide a of the objects studied when the biological effects are researched(first column), and when epidemiological studies are conducted (second column). The third column presents the symptoms most commonly attributed to electromagnetic fields by individuals experiencing them; 57 symptoms have been listed to date. ${ }^{28}$

Table 1. biological responses searched, epidemiology and symptoms attributed to radio frequencies

\begin{tabular}{|c|c|c|}
\hline $\begin{array}{l}\text { Biological and clinical effects } \\
\text { (Radio frequencies) }\end{array}$ & $\begin{array}{c}\text { Epidemiology } \\
\text { (Antennas, } \\
\text { mobile phone handset) }\end{array}$ & $\begin{array}{l}\text { Attributed Symptoms } \\
\text { (Exposure to electromagnetic fields) }\end{array}$ \\
\hline $\begin{array}{l}\text { - } \text { Genetic expression and protein synthesis } \\
\text { - } \text { radicals } \\
\text { - } \text { Genetic material (DNA) } \\
\text { - Apoptosis } \\
\text { - } \text { Development of cancer in the animal } \\
\text { - } \text { Immunological system } \\
\text { - } \text { Nervous system } \\
\text { - } \text { Development } \\
\text { - } \text { Reproduction } \\
\text { - Hearing } \\
\text { - } \text { Ocular system } \\
\text { - Cardiovascular system } \\
\text { - Melatonin } \\
\text { - Cellular proliferation } \\
\text { - Erythropoiesis in the rat } \\
\text { - Stem cell precursors in the mouse } \\
\text { - Ornithine decarboxylase (ODC) activity } \\
\text { - Endocytosis } \\
\text { - Mitosis }\end{array}$ & $\begin{array}{l}\text { - Aggregates of cancer cases (antennas) } \\
\text { - Temporal trends of impact and of } \\
\text { mortalities from brain tumors } \\
\text { - Brain tumors linked to proximity of DECT } \\
\text { base stations } \\
\text { - Glial tumors } \\
\text { - Meningiomas } \\
\text { - Acoustic neuroma } \\
\text { - Parotid tumors } \\
\text { - Pituitary gland tumors } \\
\text { - Testicular cancer } \\
\text { - Breast cancer in men } \\
\text { - Ocular melanoma }\end{array}$ & 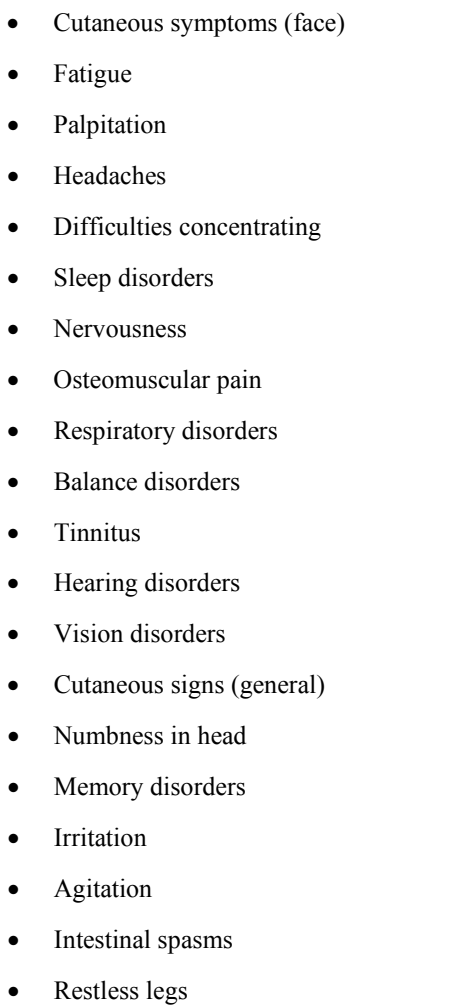 \\
\hline
\end{tabular}


While these lists are not exhaustive, they nonetheless show the com plexity of the topic and of the various approaches taken. The question remains how the results of scientific studies can become informative content to be broadcast by the media and brought to the attention of the public and how, in com bination with other social representations, they can b ecome issues of concern. Research has shown that both the media and the public devote their attention more frequently to the information related to the absence of established causality and to the unlikelihood of the health risk. This also appears to be the case for radio frequencies. Moreover, risk information is not limited to input from research; there is indeed a wide array of anec dotal accounts on $m$ obile phones in the media as well as reports from activists opposed to this technology.

\section{Links between risk information and health}

In this section, we will confront the question of a possible link between health and ris $\mathrm{k}$ information concerning radiofrequency technology, and in particular the mobile phone, by considering the various levels of information available to the public.

The first level of information on a risk is provided by the actual presence of physical objects in the hum an environment. A study on this subject deals with radon and high voltage lines, as two cases of radiat ion risk which produced various levels of atte ntion among local populations and experts. ${ }^{29}$ Considering their similarities, these cases and that of RF might be lumped together, qualifying this grouping with the fact that the hazardous nature of radon was scientifically confirmed. The study shows that public attitudes towards power lines differ according to the level of estimated "exposure". This exposure was defined in this context in terms of spatial proximity to high tension lines more or less visible to a community. The researchers involved in the study concluded that the results were based on the visual information used by the " exposed" subjects, their awareness of the threat due to elec tromagnetic fields being measured by the following question: "Can you see the high tension lines from one or several windows of your house?" This observation regarding the effects of visual exposure is int eresting in that it reveals that concerns about and occasional complete rejection of the radiation emitting source begins their visual identification. The situation might be similar for mobile phone base stations as self declared base station neighbors were found be more strained than others.

The notion of exposure in the domain of risk first relates to the approaches used in toxicology or epidemiology to look for dose-effect relation. Taken in another sense, the notion of exposure allows the effects linked to the proximity of the antennas to be taken into consideration when they are stigmatized as potentially harmful to health.

During an audition for the AFSSET risk assessment ${ }^{10}$, an expert from the U.K., L. Challis, reported that a) $90 \%$ of the concerns in five different cities of United Kingdom related to antennas and b) general practitioners mentioned an association between the fear of the base station and the production of symptoms: "We also talked to doctors and they said that fears about base stations could produce real physical symptoms. We cannot ignore these fears and the physical effects they can lead to".

Though dependent on the accounts of do ctors, this evaluation remains imprecise and the idea that fear may possibly impact health must be considered hypothetical. As a "signal" necessitating further investigation, these reactions raise questions about the mechanisms associated with the production of symptoms. In the present paper, the etiological aspect of the clinical symptoms is disc ussed relative to $t$ heir position at $\mathrm{t}$ he intersection between human beings, with cognitive and physiologic components, and their environment, in the broadest sense of the word. The underlying biological mechanism, poorly documented to date, will not be addressed.

We propose to explore three distinct categories of concepts: nocebo, stress, a nd the symmetry rule. The nocebo effect describes the negative side of the placebo effect, where a medication or a neutral medical action produces symptoms (adverse to h uman health in this case). As previously mentioned several studies have shown this effect where symptoms appeared when the EHS subjects were submitted to simulated exposure but believed to be exposed to radio frequencies.

The effect of stress could also apply if we consider that the network antennas present in the environment, along with the disturbing stigma and controversies which surround them, constitute a chronic stressor. Various symptoms of stress could then also be p otentially associated with the prevalence of the se antennas as a cause.

In contrast to these two relatively established concepts, attempts to demonstrate the 1 ink between cognition (in the larger sense of risk inf ormation being received and processed by individuals) and health are more recent. It has been found in studies concerning the rule of s ymmetry that such a link does indeed exist. Briefly, this finding can be presented with the help of a case involving transgenic corn in the United States. ${ }^{31}$ An association of consumers alerted the public that traces of transgenic corn were present in food products like taco shells, while the implicated industry maintained that transgenic corn was only used to feed livestock. The news of this incident attracted the attention of the media, and 
was quickly diffused. The Center for Disease Control (CDC) received 51 cases of persons displaying symptoms (moderate: weakness, dizziness; or se rious: fainting, symptoms requiring hospitalization), which they attributed to their exposure to transgenic corn. The CDC subsequently conducted a thorough investigation of these cases through rigorous interviews and serological tests. The results ${ }^{32}$ revealed that none of these persons had been in fact exposed to the transgenic corn, and that an allergic reaction linked to the exposure could not explain the reported symptoms. Two possibilities, not mutually exclusive, were used to ex plain this phenomenon. The first suggested that the persons who experienced an unexplained symptom prior to the alert were able to find a satisfying explanation by assuming that they were victims of transgenic corn. According to the second explanation, the warning initially disseminated by the media was itself able to incite a heightened vigilance in those who believed that they had consumed the transgenic corn and those who were thought to be thus "exposed". These two theoretical explanations illustrate the symmetry rule, ac cording to which awareness of the disease depends on the duality of representations in memory: one concrete, and the other abstract. The mental construction of a state of hea lth includes an abstract representation (for example, having consumed food products containing transgenic corn), and concrete symptoms (for e xample nausea, weakness), knowing that the presence of one of these representations could lead to the other. Thus, "persons searching for and finding representations to explain their symptoms, and searching for and finding symptoms to render their representation of the disease concrete." 33

Extrapolating from the analogy above, the transposition of $\mathrm{t}$ he symmetry rule to symptoms associated with radio frequencies would require additional studies. First, it would be necessary to specify which symptoms could be attributed to visual exposure to antennas, and which symptoms could be attributed to socio-cognitive exposure (the latter referring to receiving worrisome information about the risks of radi $o$ frequencies) and also to what extent these two exposure levels are or are not linked. Another dimension of the exposure to information would also need to be evaluated: that of presenting general advice on prudence regardless of a proven health hazard. In the case of the mobile phones, precautionary measures are often used as a means of responding to the pre occupations of the public; however, some studies explore how these measures could themselves cause or e xacerbate such worries. An experimental study conducted in Germany ${ }^{34,35}$ allowed the authors to conclude that these precautionary measures could arouse concern and amplify the perception of risk. In order to ascertain the impact of the information on the potential risks of mobile phones that is diffused by the government of the United Kingdom, researchers employ focus groups (these grou ps offer a diverse range of individuals, with different backgrounds, ages, interests, levels of sensitivity, types of preoccupations, propensities to use a mobile phone, etc.). The results show that the comprehension of the $\mathrm{m}$ essages does appe ar to be principally rooted in prec aution, and tha $t$ the precautionary advice is generally perceived as worrying rather than reassuring information. ${ }^{36}$ Another study applied as well to mobile phones in Denmark ( $n=1687)$ shows that information can increase concern in a lar ge part of the population. ${ }^{37}$ These results, obtained through different methodologies and in several countries, converge and reveal the active role of population in their interpretation of risk in formation. In this context is introduced the new IARC classification ${ }^{38}$ of RF in the $2 B$ category ("Possibly carcinogenic for humans" ), in relation to an increased risk for glioma, a malignant type of brain cancer, associated with wireless phone use. The effect of this information upon risk perception of RF is uncertain and ought to be studied.

Finally, it must be said that these three concepts (nocebo, stress and the symmetry rule) are not exclusive and can overlap. Although they cannot fully explain the complex underlying physiological mechanisms, they allow us to think about a transversal approach. Research hypotheses relevant to any discussion of the link between information and health in the case of mobile phones need to be explored even before taking into account the many methodological and theoretical difficulties. The notion of socio-cognitive exposure also dese rves serious consideration, particularly so as to more precisely define the information in its individual and collective dimensions. Indeed, in this complex context, the information simultaneously comprehends the var ious content, be it technical or symbolic, as w ell as the processes and interactions within society that contribute to the construction of mobile phones as a social object. Properly addressing this issue would require an interdisciplinary approach involving analysis in both the social and biomedical domains.

\section{Conclusion}

Expanding on the assessment of radiofrequency health risks, several points have been analyzed in consideration of the relationship between risk information and health. In sum, the relationship remains paradoxical: despite many studies that have failed to prove the existence of adverse health consequences, concerns over their potential danger persist even as cell phone handsets continue to sell well and new wireless communication networks continue to grow.

Published by Atlantis Press

Copyright: the authors 
The first element of th is somewhat counterintuitive reality is the difficulty of communicating the absence of an established health risk $w$ hen the opposite belief prevails in a society. This contrasts with the past roughly forty years, which were characterized by difficulty in managing and communicating to the public the threat of an accidental or chronic risk even when it was c learly established in various contexts. This ne w era, w hich began with the dawn of mobile phones, is defined in many countries by a general awareness and attentiveness to the possibility of health risks. Made $r$ elevant by mobile phones, it would need to be verified if this phenomenon occurs with other objects also characterized by similar technical and symbolic dimensions (potential social objects), as would be the case with the largely invisible, yet ever-present nanotechnologies.

It was interesting to no te that since the 1990 s the number of s cientific papers on mobile telephones' biological and health effects closely follows the exponential development of this technology during this period. Furthermore, social considerations were responsible for the initiation of the first st udies and have also been used, alongside scientific arguments, to justify the need for further studies (and related fund). The social role of sc ientific research is evi dent when risk assessments are repeated, though scientific knowledge is for the most part alre ady established. This social role ought to be better understood. Notably, it can contribute indirectly to the appropriation of a technology by the population since it takes into consideration concerns and social mobilizations. However, controversies and public mobilization are not indicative of the nature or severity of risk, and public health efficiency relies upon mortality and morbidity indicators. The public is not only exposed to the physical agent constituted by radio frequencies, but also to the mobile phone as a social object whose prevalence throughout society has been rapidly imposed and ha $\mathrm{s}$ become normal in most professional and private contexts. In that sense, a special "a wareness" of the presence of mobile phone base stations has set in.

Aside from the findings of the many research studies and collective reports looking for biological and health effects, including studies regarding the symptoms and various phenomena attributed to exposure to radio frequencies, another level of exposure is left to consider. Socio-cognitive exposure is manifested by the quantity and content of risk information provided to large parts of the population. The question of the social importance and health impact of such $w$ orrying information has been investigated and se veral concepts have been discussed: nocebo, stress, symmetry rule. From the perspective of their concrete integration into risk assessment, the notions explored here should be further studied in expology and through interdisciplinary research, in particular to better understand the individual and collective dimensions of the link between risk information and health.

\section{Acknowledgements:}

As members of the French Agency for Health and Environmental Safety (AFSSET) working group, the authors are indebted to the work setting provided by this institution and to the exchanges with the other experts. The points of view expressed in this article are those of the authors and involve their sole responsibility. The full expertise report is available on line: htpp//www. afsset. fr/upload/bibliotheque/049737858004877833136703438 564/ Rapport_RF_final_25_091109_web.pdf.

On line references were last consulted in October 2011.

\section{References:}

1. P. Slovic, The perception of risk. (Earthscan Publication Ltd, London, 2000).

2. N. Pidgeon, R. Kasperson, \& P. Slovic (eds.), Risk Communication and social amplification of risk. (Cambridge: Cambridge University Press, 2003)

3. Siegrist, M., Earle, T. C., Gutscher, H . and Keller, C., Perception of Mobile Phone and Base Station Risks. Risk Analysis,25(2005):1253-1264.doi:10.1111/j.1539-6924.2 005.00672.x.

4. M. Baram, The right to know and the duty to disclose hazard information, American Journal of Public Health, 74(4) (1984): 385-390

5. J. L. Greeno and J. S. Wilson, New frontiers in environmental, health and safety management, in R. Kolluru, S. Bartell, R. Pitblado and S. Stricoff (eds.) Risk Assessment and Management Handbook for Environmental, Health, and Safety Professionals. (McGraw-Hill, New-York, 1995).

6. L. Kheifets, J. Swanson, S. Kandel, and T. F. Malloy, Risk Governance for Mobile Phones, Power Lines, and Other EMF Technologies. Risk Analysis, 30(2010): 1481-1494. doi: 10.1111/j.1539-6924.201 0.01467.x.

7. ICNIRP, ICNIRP Statement on the guidelines for limiting exposure to time varying electric, magnetic and electromagnetic fields (up to $300 \mathrm{GHz}$ ), ICNIRP Statement(2009)http://www.icnirp.org/Documents/StatementEMF.pdf.

8. Institute of Electrical and Electronics Engineer, IEEE standard for safety levels with respect to human exposure to radio frequency electromagnetic field, $3 \mathrm{kHz}$ to 300 Ghz. s.1. : IEEE Std C95.1(2005).

9. J.F. Viel, E. Cardis, M. Moissonnier, R. de Seze and M. Hours, Radiofrequency exposure in the French general population: band, time, location and activity variabi lity, Environ Int, 35(8) (2009).

10. AFFSET, Mise à jour de l'expertise relative aux Radiofréquences(2009)www.afsset.fr/upload/bibliothequ e/049737858004877833136703438564/Rapport_RF_fina 125_091109_web.pdf.

11. The INTERPHONE Study Group, Brain tumour risk in relation to mobile telephone use: results of the 
INTERPHONE international case-control study, Int $J$ Epid, (2010).

12. ICNIRP, "Blue book" Exposure to high frequency electromagnetic fields, biological effects and health consequences (100 kHz-300 GHz) - Review of the Scientific Evidence and Health Consequences, (ICNIRP , Munich, 2009).

13. Executive agency for health and consumers, Promoting healthy environment with a focus on the impact of actions on electromagnetic fields, Final Report August 2010 (2010).

14. SSMs Independent expert group on electromagnetic fields for Swedish radiation safety authority, Seventh annual report, Recent research on EMF and health risk (2010).

15. WHO, Electromagnetic fields and public health: mobile phones, Fact sheet (193) (2011), http://www.who.int/ mediacentre/factsheets/fs193/en/index.html.

16. J.-P Marc-Vergnes, Electromagnetic hypersensitivity: The opinion of an observer neurologist, C.R. Physique, 11 (2010).

17. G. J. Rubin, R. Nieto-Hernandez and S. Wessely, Idiopathic environmental intolerance attributed to electromagnetic fields (formerly 'electromagnetic hypersensitivity'): An updated systematic review of provocation studies, Bioelectromagnetics, 31(1) (2010).

18. R. Szemerszky, F. Köteles, R. Lih i and G. Bárdosa, Polluted places o $\mathrm{r}$ polluted minds? An experimental sham-exposure study on background psychological factors of symptom formation in "Idiophatic Environmental Intolerance attributed to electromagnetic fields", Int J Hyg Envir Heal, 213 (2010).

19. WHO, Electromagnetic hypersensitivity, Fact sheet N²96.(2005)http://www.who.int/mediacentre/factsheets/ fs $296 /$ en/index.

20. O. Renn, Risk Governance: Coping with uncertainty in a complex world. (Earthscan, London, 2008).

21. European Commission. Electromagnetic Fields, EC, Brussels, (2007), available on li ne: available on line: http://ec.europa.eu/public_opinion/.../ebs_272a_en.pdf.

22. New York Times, Persistent Theory of Wireless (Peril French Press Attributes Many Explosions to Hertzian Waves, May 10, 1914).

23. D. von Winterfeldt, W. Edwards, Patterns of Conflict about Risky Technologies, Risk Analysis, 4 (1) (1984): 55-68.

24. M. Poumadère, C. Mays, S. Le Mer And R. Blong, The 2003 Heat Wave in France: Dangerous Climate Change Here and Now, Risk Analysis, 25(6) (2005): 1483-1494.

25. O. Borraz, M. Devigne and D. Salomon et, Controversy and protest around mobile phone antennas in France, in C. del Pozo, D. Papameletiou, P. Wiedemann, and P. Ravazzani (dir). Risk Perception and Risk Communication: Tools, Experiences and Strategies in Electromagnetic Fields Exposure, (Rome, Consiglio Nationale delle Ricerche (CNR), 2006) 94-106.

26. European Commission. Special Eurobarometer: Electromagnetic Fields, EC, ( Brussels, 2010), available on line:http://ec.europa.eu/public_opinion/archives/ebs/ebs 347 fr.pdf.

27. OECD (2008) OECD in Numbers - Year 2008. Paris : OECD Editions.
28. S. Eltiti, D. Wallace, K. Zougkou et al., Development and evaluation of the electromagnetic hypersensitivity questionnaire, Bioelectromagnetics, 28(2) (2007): 137-51.

29. W. Poortinga, P. Cox, N. Pidgeon, The Perceived Health Risks of Indoor Radon Gas and Overhead Powerlines: A Comparative Multilevel Approach, Risk Analysis, 28(1) (2008): 235-248.

30. C. Augner and GW. Hacker, Are people living next to mobile phone base stations more strained? Relationship of health concerns, self-estimated distance to base station , and psychological parameters. Indian J Occup Environ Med. 13(3) (2009): 141-145.

31. S. Brownlee, H. Leventhal, Leventhal E.A. Regulation, self-regulation, and construction of the s elf in the maintenance of physical health. In:M. Boekartz, P.R. Pintrick, M. Zeidner, Handbook of Self-Regulation. Research, theory and applications, (San Diego, CA: Elsevier Academy Press, 2000): 369-93.

32. CDC. Investigation of Human Health Effects Associated with Potential Exposure to Genetically Modified Corn. Center for Disease Control: Report to the U.S. Food and Drug Administration, (2001) 24.

33. N. T. Brewer, W. K. Hallman , H. M. Kipen, The symmetry rule: a s even-year study of symptoms and explanatory labels among Gulf War veterans, Risk Analysis, 28(6) (2008): 1737-48.

34. P. M. Wiedemann, H. Schütz, The precautionary principle and risk perception: experimental studies in the EMF area. Environ Health Perspect, 113(4) (2005): 402-5.

35. P. M. Wiedemann, H. Schütz, M. Clauberg, Influence of information about specific absorption rate(SAR) upon customers' purchase decisions and safety evaluation of mobile phones, Bioelectromagnetics, 29(2) (2008): 133-44.

36. J. Barnett, L. Timotijevic, R. Shepherd et al ., Public responses to precautionary information from the Department of Health (UK) about possible heal th risks from mobile phones, Health Policy, 82(2) (2007): 240-50.

37. J. B. Nielsen, A. Elstein, D. Gyrd-Hansen, H.W. Kildemoes, I.S. Kristiansen, H. Stovring, Effects of Alternative Styles of Risk Information on EMF Risk Perception, Bioelectromagnetics, 31(2010) 504-512.

38. IARC, Press release $N^{\circ} 208$, May 2011 "IARC classifies radiofrequency electromagnetic fields as po ssible carcinogenicto humans". http://www.iarc. fr/en/ mediacentre/pr/.../pr208_E.pdf. 